\title{
A Teoria da Conjuntura e a Crise Contemporânea
}

\section{Carlos Eduardo Martins*}

\begin{abstract}
Resumo: O artigo propõe em sua primeira parte a construção de uma teoria da conjuntura a partir da articulação dos enfoques do sistema mundial, da dependência e da revolução científico-técnica. Na segunda parte, se dedica a aplicação deste enfoque para a análise da crise do 2008-10 e seus desdobramentos na década que se inicia.
\end{abstract}

Palavras-chave: coyuntura, crise, ciclos, capitalismo, longa duração.

\section{La Teoría de la Coyuntura y la Crisis Contemporánea}

Resumen: El artículo propone en su primera parte la construcción de una teoría de la coyuntura a partir de la articulación de los enfoques de sistema mundial, de la dependencia y de la revolución científico-técnica. En la segunda parte, se dedica la aplicación de este enfoque para el análisis de la crisis del 2008-10 y sus desdoblamientos en la década que se inicia.

Palabras clave: coyuntura, crisis, ciclos, capitalismo, larga duración.

\section{The theory of Juncture and Contemporary Crisis}

\begin{abstract}
The article proposes in its first part the elaboration of a theory of the conjuncture built upon the articulation of the approaches of world-wide system, dependency theory and the technical-scientific revolution. In the second part, it focuses on the application of this approach for the analysis of the 2008-10 crisis and its deployments in the starting of the ongoing decade.
\end{abstract}

Key words: juncture, crisis, cycles, capitalism, long term.

Recibido: 19.10.2009 Aceptado: 12.11.2009

\section{Premissas Teóricas e Metodológicas para a Análise das Conjunturas}

A crise da economia mundial iniciada em 2008 tem causado grande impacto sobre os meios de comunicação e o pensamento social. Mais que uma simples recessão, apresenta, de fato, elementos de depressão ao produzir um intervalo de crescimento negativo, o que leva a muitos a caracterizarem-

\footnotetext{
*Universidade Federal do Rio de Janeiro, Rio de Janeiro. Brasil. Email: cadu.m@uol.com.br
} 
na como uma reedição da grande crise de 1929. Terá procedência esta comparação? Como podemos interpretá-la? Quais os seus determinantes e o seu alcance? Que mudanças político-ideológico e na conjuntura pode suscitar? Essas questões são de enorme pertinência não apenas para as ciências sociais, mas também para a ação política.

Vivemos um período de grande aceleração do tempo histórico provocado pelas amplas transformações materiais e sociais trazidas pela globalização. Essa aceleração produz choques, contradições e entrelaçamentos de tendências e contra-tendências. Distinguir a articulação específica das forças sociais que se combinam e confrontam nas realidades que se apresentam, é de importância central para identificarmos sua perenidade e nexo histórico. È alto o risco de se tomar fenômenos transitórios e aparentes por profundos e estruturais, em função do dinamismo de nosso tempo, o que exige do pesquisador uma extrema cautela. Para lidar com esta temporalidade, onde o fluxo histórico se intensifica, estabelecendo simultaneamente vínculos crescentes entre o futuro e o passado, a investigação social deve buscar os instrumentos conceituais de longa duração, submetendo-os permanentemente ao crivo dos processos empíricos. A construção da ciência na contemporaneidade exige cada vez mais a articulação crescente entre o abstrato e concreto, entre retrospectiva e prospectiva para teorizar a história simultaneamente como fluxo e estrutura.

Esta perspectiva tem sido particularmente desenvolvida nas ciências sociais pelo amplo movimento que busca aproximar as correntes de pensamento braudeliano e marxista e encontra sua expressão mais avançada no desenvolvimento de uma teoria do sistema mundial. Para isso concorrem as análises do sistema mundo, desenvolvidas em especial por Immanuel Wallerstein e Giovanni Arrighi; as contribuições da teoria marxista da dependência, elaboradas principalmente por Theotonio dos Santos e Ruy Mauro Marini, pensadas pelos autores como a etapa inicial da construção de uma teoria do sistema mundial; as teorias da revolução científico-técnica, fortemente inspiradas nos Grundrisse e em O Capital ; e as teorias dos ciclos longos.

A obra de Fernand Braudel constitui uma referência indispensável para a construção de conceitos de longa duração. Ele aponta a existência de múltiplas dimensões do tempo, diferenciadas, simultâneas e articuladas, que condicionam-se reciprocamente e configuram um movimento dialético de deslocamento: são a das estruturas, conjunturas e do cotidiano. As estruturas constituíram as prisões da longa duração que se moveriam lentamente, desgastando-se, e condicionando as possibilidades do existir. As conjunturas seriam inflexões cíclicas que afetariam as primeiras, incorporando-se a seu movimento de desenvolvimento e desgaste. E o cotidiano, inscrito nos marcos gerais estabelecido por estruturas e conjunturas, representaria a composição anárquica e altamente imprevisível do dia-dia que interage com as dimensões anteriores. 
Este enfoque foi amplamente desenvolvido, no Fernand Braudel Center, por Immanuel Wallerstein e Giovanni Arrighi. Immanuel Wallerstein (1979, 1984 e 1998) designou através do conceito de moderno sistema mundial a estrutura do que chama de capitalismo histórico. O moderno sistema mundial representa a combinação entre a economia-mundo capitalista, seus fluxos de capitais e mercadorias, e a superestrutura que lhe permite o controle do poder político: o sistema inter-estatal. Para Wallerstein, o capitalismo constitui a gênese de sua estrutura de poder desde o século XVI com a construção de uma economia euro-americana. Através dela libertou as trocas de longa distância dos custos políticos exigidos pelos impérios, ampliou o mercado mundial para incluir a oferta de suprimentos básicos à Europa Ocidental e criou uma estrutura econômica monopólica, voltada para a obtenção do superlucro. Essa estrutura desenvolveu o sistema inter-estatal, a partir do século XVII, como o eixo de uma superestrutura jurídico-política para o protagonismo do capital e sua mundialização. Ao limitar a territorialidade do poder coercitivo, o sistema inter-estatal estabeleceu uma assimetria espacial entre o capital e os Estados, em favor do primeiro. Esse se aproveita da competição estatal pelo capital circulante para impôr seus interesses, invertendo a relação entre os poderes econômicos e políticos, tal como era configurada nos grandes impérios da antiguidade e, em menor medida, na medievalidade.

Giovanni Arrighi (1996, 1999 e 2008) analisou com precisão a forma de coordenação do moderno sistema mundial. Ele aponta que esta se realiza por hegemonias que limitam a anarquia e estabelecem padrões monetários, jurídicos, ideológicos organizadores do sistema inter-estatal. As hegemonias combinam consenso e coerção, utilizando a força como um recurso em última instância. Trata-se de um padrão que se desenvolve não apenas no plano inter-estatal, mas também no intra-estatal, uma vez que a reivindicação da legitimidade no plano internacional por um Estado vincula-se à capacidade de garanti-la internamente. Para um Estado reivindicar com êxito a hegemonia deve possuir um grau bastante assimétrico de poder econômico (produtivo, comercial e financeiro) sobre os demais. Assimetria, segundo Wallerstein, que lhe permita vender seus produtos no mercado competidor a um preço mais baixo que os produtores locais. Nem sempre é necessária a liderança militar, embora ela seja freqüente, mas ao menos um equilíbrio geopolítico de forças que impeça o Estado mais poderoso de exercê-la contra a liderança econômica, caso das Províncias Unidas, derrotada militarmente pela Grã-Bretanha durante sua hegemonia, e da cidade de Gênova, protegida pela Espanha. Cada hegemonia amplia o liberalismo global, isto é, o grau de circulação de capitais e mercadorias na economiamundo, o espaço territorial desta, e os mecanismos de consentimento em que se baseia - representação política e sua amplitude social. Todavia, as formas ideológicas de que se utilizará para isso são complexas e diferem bastante entre si.

As hegemonias configuram os ciclos políticos-institucionais do capitalismo histórico. Oscilam pendularmente entre as formas cosmopolitasimperialistas e as corporativas-nacionalistas. Ambas aumentam a densidade 
do moderno sistema mundial, isto é, os volumes absoluto e relativo de trocas e investimentos internacionais, desenvolvendo as tendências seculares do capitalismo histórico. As hegemonias cosmopolitas-imperialistas introduzem inovações político-institucionais que ampliam radicalmente os limites espaciais da economia-mundo, e as corporativas-nacionalistas implementam profundas modificações organizacionais, mas conservam em grande parte os limites espaciais anteriores. Os ciclos se dividem em fases de expansão material e financeira. São intermediados por períodos de caos sistêmico que correspondem a guerras mundiais de aproximadamente 30 anos, proporcionais em extensão à dimensão da economia-mundo. As guerras destroem anarquicamente os excessos de competição e capacidade internacionais e, com eles, parte da densidade do sistema mundial, para relançá-lo em outra etapa de desenvolvimento.

Cada oscilação do pêndulo corresponde à combinação entre duas perspectivas temporais simultâneas: a do retorno cíclico e da irreversibilidade do tempo, abrindo uma perspectiva de interpretação da realidade de extraordinária fecundidade. A hegemonia de Espanha-Gênova, seguiu-se a das Províncias Unidas, posteriormente a britânica e por fim a estadunidense. A hegemonia como sistema de poder não exclui o imperialismo, mas se articula com ele, subordinando-o à sua direção.

O imperialismo é um sistema de poder que exige o controle político e territorial de um Estado ou formação social por outro. É extremamente útil para a expansão dos limites territoriais da economia-mundo e a anexação de regiões externas a ela. A vinculação da lógica capitalista às políticas territorialistas da nobreza de origem medieval foi decisiva para a conquista colonial das Américas, cujo custo não podia ser calculado em termos estritamente capitalistas. A anexação da Ásia e da África pela Europa Ocidental pôde se basear muito mais no cálculo que a conquista das Américas e, portanto, no protagonismo político das forças capitalistas e liberais, em função das disparidades militares impulsionadas pela revolução industrial européia, ainda que este elemento por si só seja insuficiente para explicá$1 a^{1}$. Uma vez estabelecida a integração econômica a uma nova divisão internacional do trabalho, o imperialismo torna-se desnecessário do ponto de vista da lógica global do sistema, uma vez que a dominação passa a repousar nas classes dominantes nativas, integradas ao protagonismo do capital internacional, como assinalaram as teorias da dependência. Entretanto, este ajuste não se fez facilmente, em função da própria dimensão anárquica e competitiva do capitalismo histórico. Projetos imperialistas dirigidos ao centro do sistema ameaçando o sistema inter-estatal foram elaborados durante as bifurcações de poder, inerentes aos períodos de caos sistêmico, sendo amplamente derrotados: A Espanha imperial, a França napoleônica e Alemanha nazista buscavam através do política/monopólio da violência subordinar a economia e prorrogar ou estabelecer sua dominação sobre o moderno sistema mundial.

\footnotetext{
${ }^{1}$ Deve-se agregar a decadência do Império Moghol (Arrighi, 1996)
} 
O conceito de capitalismo histórico utilizado pelos autores é de grande importância. Através dele analisam os processos de acumulação de capital tal como se desenvolveram historicamente, possibilitando visualizar os primórdios de sistema de dominação capitalista e suas tendências de longa duração. Identificam as tendểncias seculares dessa estrutura: a acumulação ilimitada e a tendência decrescente da taxa de lucro, como polaridades antagônicas, indissolúveis e fundamentos dos seus ciclos. Arranjos organizacionais historicamente provisórios garantem o predomínio da primeira, mas ao esgotarem-se dão lugar à primazia da segunda. Novos padrões de organização são estabelecidos, fundando-se em ultima instância nas possibilidades estruturais de desenvolvimento da acumulação ilimitada, mas se as impulsionam, desgastam-nas. Wallerstein e Arrighi partem ainda do conceito de capitalismo histórico para assinalar que a acumulação de capital vincula-se ao monopólio, sendo este produzido pela restrição da competição mediante a articulação de atores privados ao Estado. Apontam ainda que a criação de um sistema mundo capitalista precedeu o desenvolvimento da chamada revolução industrial, iniciando-se com o controle econômico e orçamentário dos Estados europeus pelos capitais comercial e usurário.

A perspectiva neo-braudeliana desenvolvida por Immanuel Wallerstein e Giovanni Arrighi representa um aporte extremamente importante para a renovação do pensamento marxista. Todavia apresenta também algumas limitações, a principal o abandono de uma teoria da mais-valia e do conceito de modo de produção. Entretanto, esses limites podem ser ultrapassados, uma vez que não são necessários e podem ser resgnificados. O conceito de capitalismo histórico articula-se bastante bem à concepção de Marx de que na transição entre modos de produção, a política joga um papel decisivo. O modo de produção capitalista iniciou-se pelo controle político da superestrutura, da mesma forma que a ditadura do proletariado é o elemento chave de organização da transição ao socialismo. Foi isto o que permitiu, no capitalismo, o posterior desenvolvimento da base econômica do modo de produção, suas forças produtivas e relações de produção, e, poderá fazê-lo, segundo Marx, num hipotético e futuro modo de produção comunista, caso o proletariado consiga impor sua hegemonia política para afirmar a transição socialista. O capitalismo criou um sistemamundo de poder onde articulou-se por 300 anos à liderança política da nobreza, controlando as políticas de Estado para impulsionar a busca de superlucro, mediante a pilhagem, colonização e o tráfico de escravos como suas principais fontes de acumulação ilimitada. Entretanto, apenas pôde se transformar de sistema mundo em sistema mundial, com o pleno desenvolvimento de suas tendências seculares mediante o estabelecimento de sua base específica de forças produtivas e relações de trabalho: a revolução industrial e o assalariamento, que impulsionaram o capital produtivo como eixo de articulação dos capitais comercial e usurário e, com ele, a instituição e expansão da taxa de mais-valia.

Se as versões braudeliana e neobraudeliana de capitalismo histórico apontam corretamente as identidades entre os distintos processos históri- 
cos de acumulação capitalista para definir, na acumulação ilimitada, o significado geral do conceito de capitalismo, falham, por sua vez, na análise das condições materiais que a impulsionam e a sustentam secularmente, tornado-se insuficientes para abordar o processo histórico de construção, desenvolvimento, desgaste e obsolescência dessa estrutura. Para isso deveriam incluir o conceito de modo de produção capitalista, cujo eixo central de forças produtivas, segundo Marx é a grande indústria.

A revolução industrial afirmou-se como o paradigma de desenvolvimento da economia mundial entre 1780-1970. Estabeleceu o princípio mecânico, desvalorizou a força de trabalho, incrementou a taxa de mais-valia e reduziu drasticamente a população empregada no campo. Durante este período, as contradições, para a taxa de lucro, entre o aumento da taxa de mais-valia e o decréscimo relativo da massa de valor representada pela força de trabalho, principalmente em função do aumento da taxa de desemprego, foram solucionadas favoravelmente com as ondas longas de elevação da produtividade, a apropriação dos excedentes gerados nas periferias e a estabilidade político-institucional do sistema.

A partir de 1970, com a convergência tecnológica microeletrônica, iniciou-se a mundialização da revolução científico-técnica. Esta estabelece o princípio automático em lugar ao mecânico, substituindo progressivamente o trabalho manual pelo intelectual. Se a revolução industrial reduziu drasticamente a proporção do trabalho agrícola, concentrando-o no setor secundário e de serviços, a revolução científico-técnica tende a fazer o mesmo com o trabalho manual, restringindo-o a uma proporção residual. Marx analisou este processo do ponto de vista lógico-histórico em o Capital e mais profundamente nos Grundrisse. Para o autor, a ciência seria uma força produtiva revolucionária, de natureza pós-capitalista, que pode apenas parcialmente ser submetida ao capital. Ele assinala que o desenvolvimento da ciência tende a zerar o valor, uma vez que este depende não do trabalho que se incorpora à produção, mas daquele que despende no processo de produção. A ciência ultrapassa o trabalho coletivo e estabelece o trabalho universal que se acumula infinitamente através das gerações, configurando um estoque de conhecimento gratuito que intervém crescentemente na produção, garantindo as necessidades básicas da humanidade. A automação tende a eliminar o trabalho da produção direta e reestrutura as qualificações da força de trabalho, ameaçando o principio da mais-valia relativa. Nesta, a produtividade vinculava-se à desvalorização da força de trabalho, substituindo o saber operário pela máquina, ampliando a taxa de mais-valia. Ao suprimir largamente o trabalho manual, a automação redefine as demandas sociais de trabalho em direção ao trabalho intelectual, vinculando a produtividade ao aumento do valor da força de trabalho, uma vez que passa a depender do aumento do tempo de formação do trabalhador. Esta contradição é resolvida pelo capital através da superexploração do trabalho: isto é, com o aumento do desemprego estrutural, se reduzem os preços da força de trabalho por debaixo de seu valor, sustentando a taxa de mais-valia. 
A automação apresenta ainda outra importante contradição para a taxa de mais-valia. Ao reduzir a massa de valor representada pela força de trabalho a uma parcela muito diminuta da jornada de trabalho, restringemse cada vez mais os impactos dos aumentos da produtividade sobre a elevação da taxa de mais-valia. Limita-se também a conversão de maisvalia extraordinária em lucro extraordinário, objetivo principal da inovação, segundo Marx. A mais-valia extraordinária amplia a massa de mercadorias sem reduzir o valor social de cada unidade, por isso, como menciona Ruy Mauro Marini, dirige-se principalmente ao consumo suntuário e gera a sua demanda a partir da economia relativa de gastos com a força de trabalho. Ao reduzir-se significativamente a economia de valor com a força de trabalho que se obtém com a inovação tecnológica, a mais-valia extraordinária encontra dificuldades de realização, pois a massa de mercadorias acrescentada pelo desenvolvimento da produtividade não encontra demanda equivalente na transferência de valor do trabalho ao capital por efeito da introdução do progresso técnico.

A revolução científico-técnica recebeu amplo tratamento teóricometodológico na obra de Radovan Richta, difundindo-se no pensamento marxista, para ganhar em Theotonio dos Santos o seu principal intérprete. O desenvolvimento da revolução cinetífico-técnica debilita estruturalmente o capitalismo histórico e faz girar o pêndulo das tendências seculares do moderno sistema mundial em favor da queda da taxa de lucro. Entretanto, este movimento é de longa duração, e se articula com outros que podem limitá-lo parcialmente e conter provisoriamente suas dimensões disruptivas. Estes movimentos são os ciclos. Além dos ciclos sistêmicos, de dimensão político-institucional, possuem grande relevância para a análise da conjuntura os ciclos de Kondratiev.

Os ciclos de Kondratiev são ondas de 50 a 60 anos de duração, divididas em fases A, de expansão, e B, de financeirização. Surgem a partir da revolução industrial e expressam a combinação entre novos paradigmas tecnológicos e organizacionais e seus efeitos sobre a taxa de lucro. O surgimento de novos paradigmas tecnológicos exige novas formas de organização do trabalho, das empresas, do Estado e novos conteúdos de políticas públicas. Entretanto, este é um processo lento. Durante o desajuste entre as dimensões físicas e organizacionais das novas tecnologias, cai significativamente a taxa de lucro e a acumulação tende a se deslocar para o setor financeiro, apoiando-se nos juros e na geração de capital fictício, o que provoca significa redução nas taxas de crescimento econômico per capita. Durante as fases em que essas dimensões se ajustam, a taxa de lucro sofre uma forte ascensão e a acumulação se reorienta para o setor produtivo, elevando significativamente as taxas de crescimento per capita. O ajuste é instável e desenvolve-se numa trajetória pontuada por inovações primárias, secundárias e terciárias. No seu conjunto, os Kondratievs descrevem fases A, divididas em retomada, prosperidade e maturidade, e fases B, em crise, depressão e recuperação. Cada uma destas sub-fases compõe períodos decenais e dão lugar aos chamados Kitchins, ciclos estudados por Marx, ligados à substituição dos meios de produção. Os Kitchins absorvem a 
tendência preponderante do Kondratiev: isto é, as fases A, deste, prolongam e intensificam o seu crescimento, ocorrendo o inverso durante a financeirização.

Os ciclos de Kondratiev foram teorizados inicialmente por Nicolai Kondratiev entre os anos 1920 e 1930, influenciaram diversas correntes marxistas, entre elas o trotskismo. Essas oscilações também foram observadas por Joseph Schumpeter e repercutiram sobre a corrente neoschumpeteriana. Todavia tanto Schumpeter quanto Trotsky procuraram lhe negar o caráter sistemático, atribuindo-lhe a condição de onda ao invés de ciclo, por razões apenas parcialmente distintas. Trotsky admitia apenas os ciclos decenais observados por Marx. Qualificava-os como endógenos e às ondas longas lhes atribuía caráter excepcional, na medida em que dependeriam supostamente de fatores externos ao processo de acumulação como as lutas de classes, as guerras, as descobertas tecnológicas ou geográficas. Schumpeter, por sua vez, considerava o capitalismo um sistema em equilibro, cabendo a fatores externos, como os empresários inovadores, lhe introduzirem dinamismo. A busca do lucro, visto como renda diferencial, por meio de inovações tecnológicas, colocaria o sistema em desequilíbrio. As inovações se desenvolveriam em cachos: inovações primárias, secundárias e terciárias se sucederiam levando o sistema a novo ponto de equilíbrio, diferente do anterior.

O pensamento neo-schumpeteriano avançou bastante na análise das ondas longas, principalmente, através das obras de Christopher Freeman e Carlota Perez. Elaborou os conceitos de paradigmas tecno-econômicos e trajetórias tecnológicas, identificou historicamente a existência de cinco grandes ondas, mas manteve o compromisso com a noção de equilíbrio schumpeteriana, que impediu a compreensão da acumulação ilimitada como parte da estrutura capitalista e dos ciclos como uma das formas de expressão do seu desenvolvimento. O pensamento trotskista alcançou alto nível de sofisticação com a obra de Ernst Mandel. Ele revisou as críticas de Trotsky aos ciclos, suavizando-as, mas manteve a dualidade endógeno/exógeno que era parte do esquema de análise do autor russo-ucraniano. Mandel assinalou que o desenvolvimento do capitalismo num sistema efetivamente mundial e o crescente controle que proporciona sobre a natureza através do progresso técnico, diminuíam a autonomia relativa de fatores como a natureza e a inovação tecnológica. Entretanto, ele apontou que a luta de classes permanecia como variável exógena ao poder capitalista, ainda que restringisse sua potencialidade libertadora ao período específico da primeira quinzena que se segue ao estalo da crise que inicia a fase B do Kondratiev.

Em verdade a polarização endógeno/exógeno é uma falsa questão para a compreensão da problemática dos ciclos. Ela é oriunda do liberalismo e da fragmentação que este provoca no pensamento social. Todo processo social constitui-se por uma articulação específica que se desenvolve sobre os elementos geográficos, territoriais, tecnológicos e culturais da vida humana que lhes são relativamente autônomos. O capitalismo criou uma poderosíssima força de articulação oriunda de suas tendências seculares, 
capaz de incorporar em grande parte a natureza e os processos sociais. Os Kondratievs são oscilações que correspondem ao desenvolvimento estrutural do modo de produção capitalista, de suas forças produtivas e relações de produção. O longo movimento pendular de ajustes e desajustes entre as dimensões materiais e subjetivas das tecnologias vincula-se ao predomínio da maquinaria, como força produtiva, sobre a condição humana e intelectual dos trabalhadores. E a alternância entre desenvolvimento produtivo e financeirização, ao protagonismo da acumulação ilimitada. A luta de classes tem sua autonomia relativa, mas não é um componente exógeno às estruturas capitalistas e à sua expressão cíclica: é inerente ao movimento dessas estruturas, desenvolve-se com a sua expansão e afeta seu curso, podendo, no limite, interrompê-lo. Entretanto esta possibilidade não é independente das condições materiais de existências, vinculadas, em última instância, à expansão do tempo secular do capitalismo. A reprodução dos Kondratievs, dos ciclos sistêmicos ou dos Kitchins assinala o protagonismo do capital na luta de classes e o desenvolvimento das estruturas capitalistas de que são parte. Os Kondratievs têm se manifestado com razoável regularidade na história do capitalismo e sido extensamente observados nos períodos de 1790/1810-17 até $1844-51 ; 1844-51 / 1870-75$ até 1890-96; 1891-96/1914-20 até 1939/45; 1939-45/1967-73 até 1991/1994; e 1991/1994 até 2015/20 (?).

A articulação entre as tendências seculares e a perspectiva cíclica permite situar a história como uma força viva, constituindo um instrumento teórico-metodológico de grande importância para a análise das conjunturas. O tempo assume múltiplas dimensões aparecendo simultaneamente como fluxo e estrutura, prospectiva e retrospectiva. A repetição cíclica ao incidir sobre outro ponto de desenvolvimento da estrutura capitalista cria uma temporalidade nova e original, ao mesmo que relança velhos temas e questões, articulando-os em outro contexto para suscitar novas respostas.

\section{A conjuntura atual e os desafios do século XXI}

Nossa tese é que a conjuntura contemporânea se caracteriza pela combinação de três movimentos simultâneos e de longa duração: a mundialização da revolução científico-técnica, a crise de hegemonia dos Estados Unidos -processos que se estabelecem desde início dos anos 1970-e um ciclo expansivo de Kondratiev, que se inicia a partir de 1994. Tanto a mundialização da revolução científico-técnica, quanto a crise de hegemonia dos Estados Unidos atuam no sentido de deprimir a taxa de lucro, mas este processo é contido pelo ciclo expansivo de Kondratiev que se inicia em 1994. Este ciclo de expansão restabelece os altos níveis da taxa de lucro e da taxa de crescimento per capita na economia mundial, mas sofre os efeitos desses processos mais longos: a taxa de crescimento per capita fica abaixo do período dos anos dourados, entre 1950-73, e da potencialidade tecnológica atual; o eixo geopolítico do crescimento da economia mundial se desloca para o Leste asiático, e a taxa de lucro se recupera com dificuldade, dependendo da difusão da superexploração do trabalho da periferia para os centros decadentes, onde se situa por debaixo dos níveis do pós-guerra. 
A fase A desse Kondratiev divide-se em retomada, que se institui entre 1994-2000; em prosperidade, que se estabelece entre 2002-2008; podendo-se projetar a maturidade possivelmente para 2010-2015/20. O fim do ciclo longo expansivo faria convergir os três grandes movimentos de queda da taxa de lucro, tornando-se altamente provável que lance a economia numa longa depressão e abra um período de crise geral do sistema capitalista, de caos sistêmico, similar ao de 1914-45. Os períodos de crise geral do sistema combinam o esgotamento da trajetória dos padrões organizacionais econômicos e políticos vigentes. Nesse sentido, a crise de 2008-2010, apesar de trazer elementos de depressão seria apenas um curto período de transição para uma nova expansão de aproximadamente 5-10 anos. Ela se diferencia amplamente da crise de 1929: seu epicentro é um centro decadente e não o dinâmico da economia mundial e tampouco, pode de ser caracterizada como uma crise geral do capitalismo, que envolva uma ruptura dos seus padrões políticos de organização. O aumento da intervenção estatal e o desenvolvimento do capitalismo de Estado, que a crise vem provocando, não é uma ruptura com os padrões neoliberais que organizam a economia mundial desde os anos 1980. O aumento da intervenção estatal e sua vinculação ao setor financeiro têm sido amplamente praticados pelo neoliberalismo e ainda que haja certo recrudescimento de medidas protecionistas, não há sinais de que estas possam limitar uma nova expansão do comércio mundial nos próximos 10 anos. A profundidade da crise de 2008, todavia, indica a existência de uma crise estrutural em marcha.

Durante os anos 1990, ainda sob a influência da crise mundial dos anos 1980, se manejou a idéia que viveríamos uma longa depressão. Iniciada nos anos 1970, esta se prolongaria pelo fato de o capitalismo encontrar sua etapa superior num regime de acumulação ideal, financeirizado, pautado numa moeda flexível e na força das armas. A recuperação do crescimento entre 2002-2007 colocou em segundo plano este enfoque, mas algumas interpretações apressadas da crise de 2008 tentam restabelecê-lo. Entretanto, essas afirmações não encontram sustentação empírica ${ }^{2}$. A taxa de crescimento do PIB per capita, entre 1994-2006, de 2,6\%, mais que duplicou a do período de 1974-93, conforme os indicadores da OCDE, tabulados por Angus Maddison. A crise deverá reduzi-la - para o largo intervalo iniciado em 1994 -, afastando-a dos 2,9\% a.a de 1950-73 e aproximando-a dos 2,3\% a.a de 1939-73, quando se inclui a década do caos sistêmico dos anos 1940. Todavia, permanece muito acima dos 1,2\% a.a da fase B do Kondratiev de 1974-93. A taxa de lucro nos Estados Unidos, país que oferece condições estatísticas para calculá-la, caiu de 10,3\% para 6,5\% nos intervalos 1959/67 e 1968-92. Subiu para 8,2\% no intervalo de 1994-2007, sem recuperar o patamar da década 1960, mas nesse mesmo período se elevou

\footnotetext{
${ }^{2}$ A idéia de um império global capaz de sobrepor-se à competição e ao sistema inter-estatal para estabelecer de maneira sustentável o valor, independentemente das condições reais de produção, não encontra precedentes no capitalismo histórico e no moderno sistema mundial. Esses projetos se originaram nos períodos de caos sistêmico e buscaram submeter o sistema inter-estatal a forças pré-capitalistas, face à incapacidade dos blocos históricos que os sustentavam imporem seu protagonismo pelo poder econômico.
} 
significativamente a massa de lucros gerada pelas corporações estadunidenses fora dos Estados Unidos, o que indica níveis superiores de taxa de lucro em outras regiões da economia mundial, como a China e o Leste asiático. Em 1967, a parcela de lucros no exterior gerada pelas corporações não-financeiras estadunidenses equivalia a 5\% do total alcançado. Entre 1994-2007, esta parcela se elevou para 17\%, atingindo 23\% nas crises de 2001 e 2008 (Council of Economic Advisers, 2009).

A fase A do novo Kondratiev apresenta características muito especiais. Se, por um lado, desloca a acumulação para a taxa de lucro, as crises do modo de produção capitalista e da hegemonia estadunidense atuam sobre a recuperação da taxa de lucro, limitando-a. A automação reduz a massa de valor representada pela força de trabalho e estabelece a contradição entre a inovação tecnológica e a valorização do capital. A taxa de maisvalia apresenta incrementos cada vez mais medíocres e o segmento de alta produtividade incorpora uma parcela restrita do conjunto dos trabalhadores. A conversão de mais-valia extraordinária em lucro extraordinário apresenta dificuldades: a economia de valor produzida pela substituição da força de trabalho por maquinaria, que transfere parte do fundo de consumo dos trabalhadores ao capital e se incorpora parcialmente ao consumo de luxo, torna-se cada vez mais insuficiente para atender às expectativas de valorização da massa ampliada de mercadorias que circula em busca do lucro extraordinário.

Tais processos levam à busca de formas complementares ao processo produtivo de valorização do capital, sem eliminar a sua centralidade, e à difusão da superexploração do trabalho como instrumento de elevação da taxa de mais-valia. A superexploração estabelece altos níveis de desemprego nos países centrais, para que os preços da força de trabalho caiam abaixo do seu valor, e gera um excedente de capital que não se reinveste no setor produtivo deles. Esse excedente de capital busca a valorização no setor financeiro ou no exterior, colocando em crise a divisão internacional do trabalho em centros, semiperiferias e periferia, e proporcionando uma janela de oportunidade aos países periféricos que forneçam uma força de trabalho com qualidade similar e mais barata que a dos países centrais.

A crise de hegemonia dos Estados Unidos se combina com essas necessidades da fase ascensional deste Kondratiev, oferecendo-lhe processos de valorização auxiliares. A sobrevalorização do dólar, que impulsiona os déficits comerciais estadunidenses, e a dívida pública norte-americana são seus principais instrumentos. O dólar sobrevalorizado e a dívida pública têm sido utilizados, desde os anos 1980, em maior ou menor grau, pelos governos estadunidenses como recursos de empoderamento econômico de sua burguesia e de atração de capitais, diante da perda de competividade dos Estados Unidos frente à economia mundial, em particular para o Leste Asiático. Entretanto estes instrumentos são limitados: fortalecem provisoriamente o poder financeiro estadunidense, mas impulsionam dívidas e debilitam o seu setor produtivo. A sobrevalorização do dólar eleva os preços de exportação em moeda estrangeira para as distintas economias 
nacionais e favorece a sustentação mundial da mais-valia extraordinária, impulsionando a migração dos investimentos da empresas estadunidenses para outras regiões, que podem pagar a força de trabalho em moeda local e realizar o valor da produção em dólar. A dívida pública, por sua vez, funciona como instrumento de criação de capital fictício ao absorver e valorizar o capital global excedente que não encontra os meios suficientes para fazê-lo no setor real da economia.

Entretanto, as taxas de juros, durante a fase expansiva do Kondratiev, tendem a se nivelar abaixo do crescimento da economia. A dívida pública, após um pico de $1979-94$, quando saltou de 33\% para 66,7\% do PIB, se estabilizou e desceu suavemente para 58\%, durante o governo democrata de Bill Clinton, em 2000. No governo Bush, a dívida pública recuperou os patamares de meados dos anos 1990, alcançando 65,5\% do PIB, impulsionada pelo aumento dos gastos militares. Mas, essa elevação foi insuficiente para atender à demanda por lucro extraordinário gerada pelo dinamismo da economia.

Durante a fase B do Kondratiev do pós-guerra, o Estado organizou através da dívida pública, o mercado de valorização do capital fictício. Entretanto, no período que se abriu a partir de 1994, não pôde fazê-lo da mesma forma. Coube ao setor privado organizar esta tarefa através da valorização de ativos financeiros vinculados ao setor real da economia: entre 1994-2000, este mercado concentrou-se nas ações da bolsa de valores estadunidense do segmento de alta tecnologia; e entre 2005-2007, nos títulos vinculados às hipotecas imobiliárias. Mas a valorização desses ativos chocou-se com os limites de demanda da economia estadunidense, uma vez que se articulava em última instância ao setor real da economia. Esta não sustentou a expansão e os preços das mercadorias necessários às expectativas de lucros dos investimentos financeiros ${ }^{3}$. Em 2001-02, o governo estadunidense baixou os juros e reduziu os impostos sobre as corporações como forma de estimular a recuperação econômica. Essas medidas aqueceram a economia, mas criaram a armadilha de uma enorme superacumulação de capital, que resultou na crise iniciada em meados de 2007 e levou à drástica intervenção do Estado para sustentar em grande parte os valores de ativos podres.

Nesse novo período de longo crescimento, o Estado eleva seus níveis de intervenção para através do exercício do monopólio da violência transferir recursos do conjunto da sociedade aos monopólios, sustentando as expectativas de apropriação de lucros extraordinários pelo grande capital, uma vez que parte significativa destes já não pode ser gerada pelo movimento específico do capital produtivo. Entretanto, como as políticas públicas se

\footnotetext{
${ }^{3}$ A difusão da superexploração do trabalho aos Estados Unidos elevou drasticamente o coeficiente de Gini que ascendeu de 0.403 para 0.47 entre 1980-2007, mantendo os salários reais em níveis inferiores aos de fim dos anos 1960 (Economic Report of The President, 2008).
} 
organizam para a sustentação da taxa de lucro o processo se dá de forma distinta: as taxas de juros deixam de ser o instrumento chave de dívida pública que se realiza através de enormes transferências dos recursos públicos. Estas buscam amortecer as contradições entre o capital produtivo e os investimentos financeiros articulados a este, de um lado, e a sustentação do lucro extraordinário. Esta é a especificidade da intervenção do Estado no novo Kondratiev, que torna obsoleta as pretensões de retorno ao velho keynesianismo de pleno emprego nos marcos do capitalismo contemporâneo.

A crise e as medidas anti-cíclicas, iniciadas ao final do governo Bush filho, implicaram no forte desgaste de liderança política do neoliberalismo, versão contemporânea do pêndulo cosmopolita-imperialista, na economia mundial. Ao ser realizada de forma concentrada, diferentemente do período Reagan-Bush pai, quando se distribuiu por mais de uma década, a intervenção desnudou os profundos vínculos de classe do Estado com o grande capital nos centros da economia mundial. O resultado foi o impulso estrutural ao desenvolvimento dos movimentos anti-sistêmicos que deverá marcar a próxima década. A eleição de Barack Obama deve ser vista como parte desse contexto.

O governo Obama enfrenta uma agenda interna e externa de pressões crescentes para mudanças sociais, políticas e econômicas, mas a sua capacidade de atendê-las é muito limitada. As perspectivas de retorno ao velho ideal social-democrata são muito improváveis. Herda uma brutal crise da economia estadunidense e dá prosseguimento a forte aumento da dívida pública para sustentar lucros extraordinários e o capital fictício. Compromete grande parte da sua capacidade de ação com os setores monopólicos e não consegue atender as demandas dos movimentos sociais e lideranças nacionalistas que se afirmam no mundo contemporâneo. Seleciona o atendimento das pressões sociais internas, uma vez que sua especificidade está na tentativa de acomodar os choques entre movimentos sociais e capital financeiro para buscar resgatar inicialmente a legimitidade interna e posteriormente externa do Estado norte-americano Entretanto, mesmo internamente suas propostas sociais são de alcance reduzido ${ }^{4}$. O elevadíssimo índice de endividamento reduzirá o potencial de crescimento estadunidense, o que limitará a posterior redução dos altos níveis de desemprego alcançados durante a crise: 9,5\% em junho de 2009, estimando-se mais de 10\% em 2010.

O comprometimento financeiro do estado norte-americano reduzirá sua capacidade de liderança para impulsionar os processos de transformação

\footnotetext{
${ }^{4}$ No informe A new era of responsibility: renewing American's promisse (2009), o governo Obama estima a elevação da dívida pública e do déficit público, entre 2008 e 2009, de $70,2 \%$ a $90,4 \%$, e $3,2 \%$ a $12,3 \%$, respectivamente. As previsões são ainda de que a dívida pública alcance aproximadamente 100\% do PIB em 2011, se mantendo neste patamar durante a década, na medida em que o déficit público apresente taxas similares ao crescimento da economia a partir de 2012, aproximadamente 3,0\%. A previsão do informe é que de 2008-2019 o pagamento do governo federal com juros aumente $178 \%$, com programas de saúde $128 \%$, com a seguridade social $86 \%$, e com a defesa $46 \%$.
} 
da economia mundial no sentido da sustentabilidade, inclusão, e paz ${ }^{5}$. Se aprofundará o deslocamento do dinamismo do crescimento econômico para o Leste asiático. Apesar da eleição de Obama, os Estados Unidos deverão continuar a perder liderança política na próxima década. A agenda mundial dificilmente será estabelecida por sua decadente hegemonia. Os governos latino-americanos tomam a iniciativa em estabelecer os temas da agenda na relação com os Estados Unidos -caso de Cuba e sua reincorporação a OEA, fim do bloqueio, restabelecimento democrático em Honduras- e a desenvolver temas próprios independentemente da participação estadunidense: novos rumos para a integração regional que contemplem a cooperação financeira, tecnológica, científica, cultural e não priorizem a competiçẫo e concorrência econômica; e a articulação política entre América Latina, Ásia e África. Abre-se um enorme espaço para reorganização geopolítica da economia mundial. Neste processo os BRICAS - caso se inclua a África do Sul - poderão jogar um papel chave.

América Latina ingressa na próxima década dividida em três grandes forças político e sociais: neoliberais, a terceira via e neo-nacionalistas. Os neoliberais mantém as políticas do consenso de Washington, o alinhamento aos Estados Unidos e situam-se à direita do espectro político, tendo seu eixo na região, em Colômbia e México; a terceira via, baseada principalmente no Brasil, Uruguai e Chile, busca combinar políticas sociais, maior independência na política externa e, no caso do Brasil, certa recuperação da indústria nacional, com as políticas econômicas neoliberais; e os neo-nacionalistas, desenvolvem o capitalismo de estado em direção a formas participativas e, nos casos mais radicais, de transição ao socialismo. O neo-nacionalismo assume em geral uma perspectiva latinoamericanista e suas maiores expressões são a Venezuela, Bolívia, Equador, Paraguai, às quais se articulam o socialismo cubano e o sandinismo na Nicarágua. A Argentina se articula com moderação e limitações a este processo.

O Brasil joga um papel central para a manutenção da hegemonia dos Estados Unidos na região. Um novo padrão de desenvolvimento para a região poderá se desenvolver com a sua aproximação ao neonacionalismo, articulando o continente a formação de um novo bloco geopolítico com Ásia e África. Mantidas as tendências atuais, a China deverá nos próximos 20 anos ser o principal parceiro comercial da América Latina, A questão que se coloca é o que significará a aproximação com a China: a reprimarização de nossas economias na esteira de uma conjuntura de elevação dos preços dos produtos primários, que deverá permanecer na próxima década, provocada pela expansão da demanda chinesa; ou a utilização deste momento favorável para investir os excedentes comerciais alcançados na elevação da qualificação, saúde e bem-estar de nossos povos

\footnotetext{
${ }^{5}$ A possibilidade de uma nova crise decenal na segunda metade da próxima década poderá exaurir o que resta da hegemonia estadunidense e acelerar a transição para um novo padrão monetário mundial
} 
e no aumento de nossa capacidade de gerar valor agregado?

A resposta a esta questão dependerá das lutas políticas e sociais na região. Caso predomine a articulação entre neoliberais e terceira via, a reprimarização de nossa economia aprofundará as desigualdades internas, a superexploração do trabalho, provocará o fortalecimento da fração agroexportadora nas burguesias locais, produzindo um período de crescimento econômico ecologicamente predatório e de baixa sustentabilidade. Caso o neo-nacionalismo consiga atrair para si o centro político da região, poderse-á se abrir o espaço para um novo desenho de políticas públicas com impactos não apenas regionais, mas globais rumo à transição a um mundo multipolar. 


\section{Referências Bibliográficas}

Arrighi, G. (1996), O longo século XX. Contraponto, Rio de Janeiro.

Idem (1997), A ilusão do desenvolvimento. Vozes, Petrópolis.

Arrighi, G.; Silver, B. (1999), Chaos, governance and modern world system. Minnesotta Press.

Council of Economic Adviser (2008), Economic Report of The President.

Dosn Santos, T. (2000), A teoria da dependência: balanço e perspectivas. Civilização Brasileira, Rio de Janeiro.

Freeman, C.; Clark, J.; Soete, L. (1982), Unemployment and technical innovation: a study of long waves and economic development. Francis Pinter Publishers, London.

Kondratiev, Nicolai (1992), Los ciclos largos de la coyuntura económica. UNAM, México.

Maddison, Angus (1997), La economía mundial 1820-1992: análisis y estadísticas. OCDE, Paris.

Idem (1998), Chinese economic performance in the long run. OCDE, Paris.

Idem (2001), The world economy: a millennial perspective. OCDE, Paris.

Mandel, Ernst (1980), Long waves of capitalism development: the marxist interpretation. Cambridge University Press, Cambridge.

Idem (1985), O capitalismo tardio. Abril Cultural, São Paulo.

Marini, Ruy Mauro (1973), Dialéctica de la dependencia. Ediciones Era, México D.F.

Martins, Carlos Eduardo (2008), “A conjuntura contemporânea e o sistema mundial: os desafios da América Latina no século XXI” in Paises emergentes e os novos caminhos da modernidade. UNESCO, v.1, p. 31-51, 1 ed. Brasilia.

Idem (2003), Globalização dependencia e neoliberalismo na América Latina. Tese de doutorado apresentada ao departamento de Sociologia da USP.

Marx, Karl (1985), O capital: livro 1, o processo de produção do capital. 10. ed. Difel, 2 v. São Paulo.

Idem (1983-a), O capital: livro 2, o processo de circulação do capital. 4. ed. Difel, 3 v. São Paulo. 
Idem (1983-b), O capital: livro 3, o processo global de produção capitalista. 4. ed. Difel, 6 v. São Paulo.

Idem (1987-a), Elementos fundamentales para la crítica de la economía política (Grundrisse): borrador 1857-1858, volumen 1. 15. ed. Siglo XXI, México D.F.

Idem (1987b), Elementos fundamentales para la crítica de la economía política (Grundrisse): borrador 1857-1858, volumen 2. 15. ed. Siglo XXI, México D.F.

Idem (1987-c), Elementos fundamentales para la crítica de la economía política (Grundrisse): borrador 1857-1858, volumen 3. 15. ed. Siglo XXI, México D.F.

Office of Manangement and Budget (2009), A new Era of Responsibility: Renewing America Promise‘s.

Perez, Carlota (1986), Las nuevas tecnologías: una visión de conjunto. 1986, Mimeografado.

Idem (1989), The present wave of technical change: implications for competitive restructuring for institucional reform in developing countries. Mimeografado.

Richta, Radovan (1971), La civilización en la encrucijada. Siglo XXI, México D.F.

Schumpeter, J. (1989), Business cycles: a theoretical, historical, and statistical analysis of the capitalist process. Porcupine Press, Philadelphia.

Wallerstein, I. (1979), El moderno sistema mundial I: la agricultura capitalista y los orígenes de la economía-mundo europea en el siglo XVI. Siglo XXI, Madrid.

Idem (1984), El moderno sistema mundial II: el mercantilismo y la consolidación de la economía-mundo europea 1600-1750. Siglo XXI, Madrid.

Idem (1998), El moderno sistema mundial III: la Segunda era de gran expansión de la economía-mundo capitalista, 1730-1850. Siglo XXI, Madrid. 